\title{
Usando o GeoGebra na Construção do Conceito de Derivada no Ponto
}

\author{
Ana Júlia da Silva* Natani Lacerda** Geferson da Silva* \\ Depto de Ciências Exatas e Engenharias, DCEEng, UNIJUÍ \\ 98700-000, Ijuí, RS \\ E-mail: ana_juliass@yahoo.com.br; natty.lacerda@hotmail.com; geferson_gustavo@hotmail.com
}

\author{
Lecir Dorneles Cláudia Piva A. Patricia Spilimbergo \\ Depto de Ciências Exatas e Engenharias, DCEEng, UNIJUÍ \\ 98700-000, Ijuí, RS \\ E-mail: lecird@unijui.edu.br; cpivaa@gmail.com; patspi@unijui.edu.br
}

\begin{abstract}
RESUMO
Este trabalho tem como objetivo apresentar a análise de uma oficina, desenvolvida como atividade extracurricular, realizada com um grupo de alunos do curso de Agronomia da Universidade Regional do Noroeste do Estado do Rio Grande do Sul - UNIJUÍ, a qual visava possibilitar a estes alunos, um aprofundamento dos conceitos desenvolvidos na disciplina de Matemática II, a qual enfoca conceitos de Cálculo Diferencial e Integral.

A oficina proposta, organizada conjuntamente com a professora da disciplina, foi aplicada pelos acadêmicos do curso de Matemática - Licenciatura, nas dependências do Laboratório de Matemática da referida universidade, durante o $2^{\circ}$ semestre do ano de 2013. A mesma consistiu em atividades utilizando o software GeoGebra, visando a construção do conceito de derivada no ponto. A opção pelo GeoGebra se deu, pelo mesmo ser disponibilizado gratuitamente e ainda oferecer diferentes possibilidades que permitem, a construção de conceitos, através de simulações gráficas, além de, reforçar a importância do uso de softwares em aula de matemática [1].

Como evidencia Simon [2], sobre as Trajetórias Hipotéticas de Aprendizagem, é necessário que os professores de matemática estabeleçam hipóteses sobre os conhecimentos prévios de seus alunos, para que possam idealizar a trajetória ou desenvolvimento das situações de aprendizagem de suas aulas. Dessa forma, a oficina foi elaborada considerando o conhecimento que os alunos já possuíam e o conhecimento que eles precisavam possuir para entender o conceito de derivada, corroborando com esta teoria, quando aponta a importância de uma trajetória de aprendizagem, na tentativa de sanar dificuldades e construir conceitos.

Assim, com este propósito, inicialmente na oficina foi apresentando aos alunos os conceitos de reta tangente e secante a uma curva qualquer. Na sequência, o grupo escolheu a curva quadrática, $\mathrm{f}(\mathrm{x})=\mathrm{x}^{2}+2 \mathrm{x}$, para representá-la no software e a partir dela realizar as construções das retas. Após as orientações iniciais de uso do GeoGebra, e a representação da curva quadrática, os alunos construíram um ponto fixo e outro deslizante sobre esta curva, para assim representar a reta secante e a reta tangente. A partir desta construção os alunos realizaram movimentos com o ponto deslizante tendendo ao ponto fixo, e com isso observaram a variação do coeficiente angular da reta secante se aproximando ao coeficiente angular da reta tangente, para um incremento de 0,1 .

Após as construções realizadas no GeoGebra, foi solicitado aos alunos para desenvolverem manualmente o cálculo da derivada da função inicial (quadrática) no ponto fixo, através da definição $f^{\prime}\left(x_{0}\right)=\lim _{x \rightarrow x_{0}} \frac{f(x)-f\left(x_{0}\right)}{x-x_{0}}$. Ao encontrar a indeterminação, os alunos resolveram o limite por aproximação para um incremento de 0,1 , anterior e posterior ao ponto fixo. Esse encaminhamento foi realizado para que os alunos percebessem que o resultado obtido, se aproximava ao valor correspondente ao coeficiente angular da reta tangente.
\end{abstract}

\footnotetext{
* Alunos do Curso de Matemática Licenciatura.

** Aluna do Curso de Matemática Licenciatura e Bolsista de Iniciação Científica PIBIC/CNPq
} 
Durante todo o desenvolvimento da oficina, foram propostas discussões e questionamentos, no sentido de desenvolver o raciocínio dedutivo acerca dos conceitos e possibilitar a aprendizagem significativa, pois, concordando com Vygotsky [3], quando este aponta que "a verdadeira trajetória de desenvolvimento do pensamento não vai no sentido do pensamento individual para o socializado, mas do pensamento socializado para o individual", uma vez que, é a partir das discussões em grupo que os alunos construirão seus entendimentos acerca dos conceitos apresentados.

Além disso, vale ressaltar que os alunos, motivados pelo uso do software e pela possibilidade de aprofundamento de conceitos já desenvolvidos, mostraram-se participativos e atuantes nesta oficina atingindo o objetivo proposto inicialmente, ou seja, compreendendo o conceito de derivada no ponto com mais significado, fatos estes evidenciados na participação destes alunos nas aulas subsequentes.

Palavras-chave: GeoGebra, Derivada, Atividade Computacional.

\section{Referências}

[1] L. Dorneles; C. Piva; P. Spilimbergo; V. Roncaglio, Reelaborando conceitos de matemática através de atividades computacionais, em "XI Encontro Nacional de Matemática - XI ENEM", 1 CD-ROOM, Curitiba, 2013.

[2] M. A. Simon y R. Tzur, Explicating the role of mathematical tasks in conceptual learning: an elaboration of the hypothetical learning trajectory. Mathematical Thinking and Learning, 6(2), p. 91-104, (2004).

[3] L. Vygotsky, Pensamento e linguagem. Edição Eletrônica, Ridendo Castigat Moraes, p. 18, (2001). 